\title{
Association between serum cholesterol and eating behaviours during early childhood: a cross-sectional study
}

\author{
Navindra Persaud MD MSc, Jonathon L. Maguire MD MSc, Gerald Lebovic PhD, Sarah Carsley MSc, \\ Marina Khovratovich MD, Janis A. Randall Simpson PhD, Brian W. McCrindle MD MPH, \\ Patricia C. Parkin MD, Catherine Birken MD MSc; for the TARGet Kids! collaboration
}

\begin{abstract}
Background: Modifiable behaviours during early childhood may provide opportunities to prevent disease processes before adverse outcomes occur. Our objective was to determine whether young children's eating behaviours were associated with increased risk of cardiovascular disease in later life.
\end{abstract}

Methods: In this cross-sectional study involving children aged 3-5 years recruited from 7 primary care practices in Toronto, Ontario, we assessed the relation between eating behaviours as assessed by the NutriSTEP (Nutritional Screening Tool for Every Preschooler) questionnaire (completed by parents) and serum levels of non-high-density lipoprotein (HDL) cholesterol, a surrogate marker of cardiovascular risk. We also assessed the relation between dietary intake and serum non-HDL cholesterol, and between eating behaviours and other laboratory indices of cardiovascular risk (low-density lipoprotein [LDL] cholesterol, apolipoprotein B, HDL cholesterol and apoliprotein A1).
Results: A total of 1856 children were recruited from primary care practices in Toronto. Of these children, we included 1076 in our study for whom complete data and blood samples were available for analysis. The eating behaviours subscore of the NutriSTEP tool was significantly associated with serum nonHDL cholesterol ( $p=0.03)$; for each unit increase in the eating behaviours subscore suggesting greater nutritional risk, we saw an increase of $0.02 \mathrm{mmol} / \mathrm{L}$ ( $95 \%$ confidence interval $[\mathrm{Cl}] 0.002$ to 0.05 ) in serum non-HDL cholesterol. The eating behaviours subscore was also associated with LDL cholesterol and apolipoprotein B, but not with HDL cholesterol or apolipoprotein A1. The dietary intake subscore was not associated with non-HDL cholesterol.

Interpretation: Eating behaviours in preschoolaged children are important potentially modifiable determinants of cardiovascular risk and should be a focus for future studies of screening and behavioural interventions.
$\mathrm{M}$ odifiable behaviours during early childhood may provide opportunities to prevent later chronic diseases, in addition to the behavioural patterns that contribute to them, before adverse outcomes occur. There is evidence that behavioural interventions during early childhood (e.g., ages 3-5 yr) can promote healthy eating. ${ }^{1}$ For example, repeated exposure to vegetables increases vegetable preference and intake, ${ }^{2}$ entertaining presentations of fruits (e.g., in the shape of a boat) increase their consumption, ${ }^{3}$ discussing internal satiety cues with young children reduces snacking, ${ }^{4}$ serving carrots before the main course (as opposed to with the main course) increases carrot consumption, ${ }^{5}$ and positive modelling of the consumption of healthy foods increases their intake by young children. ${ }^{6,7}$ Responsive eating behavioural styles in which children are given access to healthy foods and allowed to determine the timing and pace of eating in response to internal cues with limited distractions, such as those from television, have been recommended by the Institute of Medicine. ${ }^{8}$

Early childhood is a critical period for assessing the origins of cardiometabolic disease and implementing preventive interventions. ${ }^{8}$ However, identifying behavioural risk factors for cardiovascular disease during early childhood is challenging, because signs of disease can take decades to appear. One emerging surrogate marker for later cardiovascular risk is the serum concentration of non-high-density lipoprotein (HDL) cholesterol (or total cholesterol minus HDL cholesterol). ${ }^{9-12}$ The Young Finn Longitudinal Study found an association between non-HDL cholesterol levels during childhood (ages 3-18 yr) and an adult measure of atherosclerosis (carotid artery intima-
Competing interests:

Navindra Persaud is an Associate Editor for $C M A J$; he played no part in the selection of or peer review process for this article. Janis Randall Simpson has received grant funding from the Canadian Institutes of Health Research (CIHR); she is a board member for the Danone Institute of Canada; she is a consultant for Dietitians of Canada; she receives royalties for NutriSTEP licences; and she has been reimbursed for travel expenses by the CIHR. Brian McCrindle is a board member for

Medpace; he has been a consultant for Eli Lilly,

Merck and Bristol-MyersSquibb; and he has received grant funding from AstraZeneca. Patricia Parkin and Catherine Birken work for institutions that have received grants from the CIHR. No other competing interests were declared.

This article has been peer reviewed

Correspondence to: Navindra Persaud, nav.persaud@utoronto.ca

CMAJ 2013. DOI:10.1503 /cmaj.121834 
media thickness), although this relation was not significant for the subgroup of younger female children (ages 3-9 yr). ${ }^{10,11}$ The Bogalusa Heart Study, which included a subgroup of children aged 2-15 years, found an association between lowdensity lipoprotein (LDL) cholesterol concentration (which is highly correlated with non-HDL cholesterol) and asymptomatic atherosclerosis at autopsy. ${ }^{12}$ The American Academy of Pediatrics recommends non-HDL cholesterol concentration as the key measure for screening for cardiovascular risk in children. ${ }^{9}$ Serum non-HDL cholesterol concentration is the dyslipidemia screening test recommended by the American Academy of Pediatrics for children aged 9-11 years. ${ }^{9}$ Cardiovascular risk stratification tools such as the Reynold Risk Score (www.reynoldsriskscore.org) and the Framingham Heart Study coronary artery disease 10-year risk calculator (www.framinghamheartstudy.org/risk) for adults do not enable directed interventions when cardiovascular disease processes begin — during childhood.

The primary objective of our study was to determine whether eating behaviours at 3-5 years of age, as assessed by the NutriSTEP (Nutritional Screening for Every Preschooler) questionnaire, ${ }^{13,14}$ are associated with non-HDL cholesterol levels, a surrogate marker of cardiovascular risk. Our secondary objectives were to determine whether other measures of nutritional risk, such as dietary intake, were associated with non-HDL cholesterol levels and whether eating behaviours

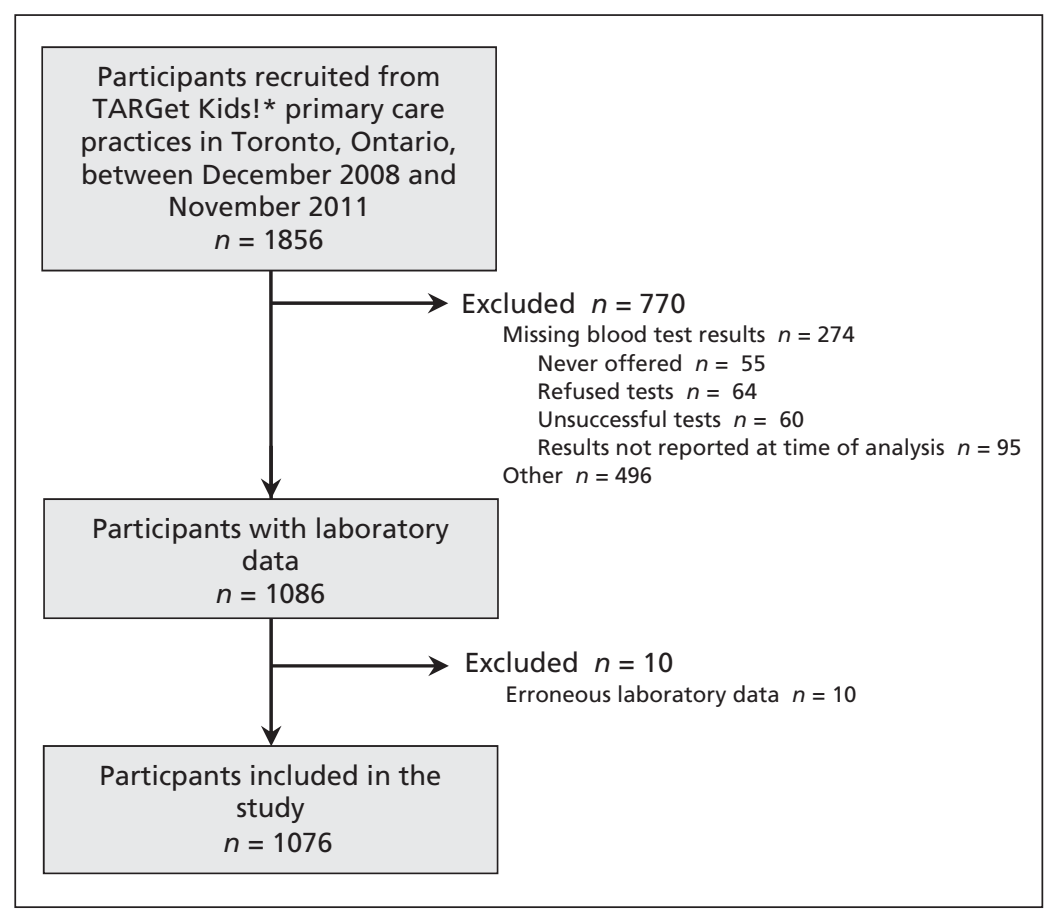

Figure 1: Recruitment of participants to the study. *TARGet Kids! is a primary care research network in Toronto, Ontario. The network currently includes 7 large group practices, each of which has between 3 and 10 practising physicians. are associated with other cardiovascular risk factors, such as LDL cholesterol, apolipoprotein B, HDL cholesterol and apoliprotein A1.

\section{Methods}

\section{Participants}

Children aged 3-5 years were recruited from the community-based primary care research network for children in Toronto, Ontario (TARGet Kids!). There are currently 7 large group practices in the network, each of which has between 3 and 10 practising physicians. Trained research assistants in the practices obtained survey data and physical measurements, and performed venous sampling on site at the primary care clinic.

\section{Study design}

In this cross-sectional study, a parent of each participant completed the NutriSTEP questionnaire. The questionnaire consists of 17 items (range of scores 0-68), with questions divided a priori into the following 5 subscales: eating behaviours, dietary intake, parental concerns about food and activity, screen time duration (television, computer or video game use) and the use of supplements. ${ }^{13,14}$ The questionnaire has been validated for use in a population of multicultural Canadian preschool-aged children, with a detailed assessment by a registered dietitian that includes nutritional history and a 3-day dietary recall; higher scores represent greater nutritional risk. ${ }^{13}$ The equally weighted items constituting the eating behaviours subscale included whether children were allowed to decide how much they ate, whether they ate while watching television, the number of meals they ate per day, the presence of gagging or trouble swallowing while eating and whether the child is not hungry at meal time because of frequent drinking. Screen time and supplements were each based on single questionnaire items, and we transformed them into categorical variables ( $>2 \mathrm{~h}$ of screen time and use of supplements "sometimes to always").

We measured the height and weight of the children and their parents using established protocols ${ }^{15}$ and standardized their body mass indices (BMIs) to z-score BMIs (zBMIs) using World Health Organization growth charts. ${ }^{16}$ Using nonfasting blood samples from the children drawn on the same day on site, we performed laboratory investigations to assess the following: lipid profile, insulin level, blood glucose level and apolipoprotein A1 and B levels. Serum samples were sent daily to a centralized research laboratory (Appendix 1, available at www.cmaj.ca/lookup/suppl/doi :10.1503/cmaj.121834/-/DC1) at Mount Sinai Services, Toronto, Ont. 


\section{Statistical analysis}

Potential confounders in the relation between eating behaviours as measured by the NutriSTEP questionnaire and serum non-HDL cholesterol concentration included child factors (age, sex, birth weight, zBMI) and parent factors (education level, ethnicity, history of gestational diabetes, BMI). We collected data on these factors using a parent-completed, standardized, data collection form. Each participant was assigned an ethnicity risk category (elevated, average or reduced) based on the reported parental ethnicities. Risk for each parental ethnicity was categorized in the same way based on observational studies of cardiovascular and metabolic risk, ${ }^{17,18}$ and each participant was assigned the highestrisk ethnicity of his or her parents for either cardiovascular or metabolic risk (Appendix 2, available at www.cmaj.ca/lookup/suppl/doi:10.1503 /cmaj.121834/-/DC1).

To assess the relation between eating behaviours (as assessed by the NutriSTEP questionnaire) and serum non-HDL cholesterol concentration, we used a multiple linear regression model adjusted for age, sex, ethnicity, zBMI, parental BMI, history of gestational diabetes and the questionnaire subscales (dietary intake, parental concern, screen time and vitamin supplements). We used similar models to meet our secondary objectives: determining the relations between eating behaviours and total cholesterol, LDL cholesterol, HDL cholesterol and apolipoproteins A1 and B. We adjusted all models for dietary intake, parental concern about feeding, screen time and use of supplements. Missing data fit the missing-at-random criterion; we used multiple imputation methods using predictive mean matching to analyze these data. ${ }^{19} \mathrm{~A}$ minimum of 5 datasets were imputed for each analysis, and adjusted variances were computed. Because only minimal outcome data were missing (22/1076 [2.0\%]), we did not perform imputation for the outcome variable of interest. ${ }^{19,20}$

We performed a sensitivity analysis to verify the effect of imputation on our results. Multicollinearity was not found to be a problem when we examined it using correlation matrices and variance inflation factors. We assessed our models by examining residual and normal quantile plots, as well as differences in beta estimates and differences in fits.

\section{Results}

A total of 1856 children aged 3-5 years were recruited between 2008 and 2011. Of these children, laboratory data were available for 1086 (Figure 1); however, the data for 10 of these par- ticipants were erroneous, and they were excluded from the study. The remaining 1076 participants included in our study were demographically similar to the children who were excluded from the study (Table 1). We were able to collect data to measure parental BMI from 185 fathers (17.2\%) and 807 mothers $(75.0 \%)$; parental data were missing for 84 participants $(7.8 \%)$.

Responses to the NutriSTEP questionnaire are shown in Table 2 . The mean ( \pm standard deviation [SD]) laboratory indices for our participants were as follows: non-HDL cholesterol $2.8( \pm 0.6)$ $\mathrm{mmol} / \mathrm{L}$, HDL cholesterol $1.3( \pm 0.3) \mathrm{mmol} / \mathrm{L}$, LDL cholesterol $2.2( \pm 0.6) \mathrm{mmol} / \mathrm{L}$, total cholesterol $4.1( \pm 0.7) \mathrm{mmol} / \mathrm{L}$, apolipoprotein A1 1.3 $( \pm 0.2) \mathrm{g} / \mathrm{L}$ and apolipoprotein B $0.6( \pm 0.1) \mathrm{g} / \mathrm{L}$. In our primary analysis, the eating behaviours subscore of the NutriSTEP questionnaire was significantly associated with serum non-HDL cholesterol

Table 1: Characteristics of participants and nonparticipants

\begin{tabular}{|c|c|c|c|}
\hline \multirow[b]{2}{*}{ Characteristic } & \multicolumn{2}{|c|}{ No. $(\%) *$} & \multirow[b]{2}{*}{$\begin{array}{c}p \\
\text { value }\end{array}$} \\
\hline & $\begin{array}{l}\text { Participants } \\
n=1076\end{array}$ & $\begin{array}{l}\text { Nonparticipants } \\
\quad n=780\end{array}$ & \\
\hline Age, yr, mean $( \pm S D)$ & $4.14( \pm 0.84)$ & $4.13( \pm 0.82)$ & 0.7 \\
\hline Sex, male & $528(49.1)$ & $393(50.3)$ & 0.6 \\
\hline BMI $z$ score, mean $( \pm S D)$ & $0.35( \pm 1.01)$ & $0.30( \pm 1.07)$ & 0.4 \\
\hline Maternal BMI, mean $( \pm$ SD) & $25.2 \quad( \pm 4.74)$ & $24.8 \quad( \pm 4.45)$ & 0.06 \\
\hline $\begin{array}{l}\text { Maternal postsecondary } \\
\text { education }\end{array}$ & $914(84.9)$ & $650(83.3)$ & 0.6 \\
\hline Gestational diabetes & $44 \quad(4.1)$ & $26 \quad(3.3)$ & 0.6 \\
\hline $\begin{array}{l}\text { Ethnicity with high cardiovascular } \\
\text { risk }\end{array}$ & $123(11.4)$ & $78(10.0)$ & 0.3 \\
\hline $\begin{array}{l}\text { Ethnicity with high metabolic } \\
\text { risk }\end{array}$ & $367(34.1)$ & $240(30.8)$ & 0.1 \\
\hline $\begin{array}{l}\text { Note: } \mathrm{BMI}=\text { body mass index, } \mathrm{SD}=\text { stan } \\
\text { *Unless otherwise indicated. }\end{array}$ & deviation. & & \\
\hline
\end{tabular}

Table 2: NutriSTEP questionnaire responses

\begin{tabular}{|llcc|}
\hline NutriSTEP score or subscore & $\begin{array}{c}\text { Item mean } \\
\text { scores }( \pm \text { SD) }\end{array}$ & $\begin{array}{c}\text { No. of } \\
\text { items }\end{array}$ & $\begin{array}{c}\text { Maximum } \\
\text { possible } \\
\text { value }\end{array}$ \\
\hline Total & $15.03( \pm 6.60)$ & 17 & 68 \\
\hline Subscore & & & \\
\hline Eating behaviours & $3.81( \pm 2.20)$ & 5 & 20 \\
\hline Dietary intake & $7.24( \pm 3.39)$ & 6 & 24 \\
\hline Parental concern & $1.41( \pm 2.47)$ & 4 & 16 \\
\hline Screen time* & $0.67( \pm 0.94) *$ & 1 & 4 \\
\hline $\begin{array}{l}\text { Supplements } t \\
\text { Note: SD }=\text { standard deviation. }\end{array}$ & $2.02( \pm 1.53) *$ & 1 & 4 \\
\hline $\begin{array}{l}\text { *Dichotomous }(\leq 2 \text { v. }>2 \text { h/d); } 149 \text { participants }(13.8 \%) \text { reported more than } 2 \text { h/d. } \\
\text { +Dichotomous (rarely/never v. sometimes to always; } 607 \text { participants }(56.4 \%) \text { reported using } \\
\text { supplements sometimes to always. }\end{array}$ & & \\
\hline
\end{tabular}


concentration ( $p=0.03$ ); for each unit increase in the eating behaviour subscore, we saw an increase of $0.02 \mathrm{mmol} / \mathrm{L}$ (95\% CI 0.002 to 0.05 ) (Table 3 ) in serum levels of non-HDL cholesterol. To avoid inflation of $R^{2}$, biased regression coefficients and standard errors, we specified all covariables a priori and left them in the final model. ${ }^{19}$ Male sex and parental BMI were also significantly related to serum non-HDL cholesterol levels (Table 3).

In our secondary analyses, no other subscales of the nutritional risk questionnaire were associ-

Table 3: Regression model showing association between serum non-HDL cholesterol level, patient characteristics and nutritional risk subscores

\begin{tabular}{|c|c|c|}
\hline Characteristic & $\begin{array}{l}\text { Adjusted* beta estimate } \\
\qquad(95 \% \mathrm{Cl})\end{array}$ & $p$ value \\
\hline Age & $-0.04 \quad(-0.09$ to 0.00$)$ & 0.06 \\
\hline Sex, Male & $-0.12 \quad(-0.20$ to -0.05$)$ & 0.001 \\
\hline Birth weight & $0.01 \quad(-0.05$ to 0.06$)$ & 0.8 \\
\hline zBMI & $0.04 \quad(-0.001$ to 0.07$)$ & 0.06 \\
\hline Parental BMI & $-0.01 \quad(-0.02$ to -0.002$)$ & 0.01 \\
\hline Gestational diabetes & $0.02 \quad(-0.17$ to 0.22$)$ & 0.8 \\
\hline $\begin{array}{l}\text { Maternal education - } \\
\text { postsecondary }\end{array}$ & $-0.02 \quad(-0.16$ to 0.10$)$ & 0.7 \\
\hline Ethnicity, elevated risk $t$ & $0.07 \quad(-0.06$ to 0.20$)$ & 0.3 \\
\hline Ethnicity, reduced risk $†$ & $0.01 \quad(-0.13$ to 0.15$)$ & 0.9 \\
\hline \multicolumn{3}{|l|}{ NutriSTEP subscore } \\
\hline Eating behaviours & $0.02 \quad(0.002$ to 0.05$)$ & 0.03 \\
\hline Dietary intake & $-0.01 \quad(-0.02$ to 0.01$)$ & 0.3 \\
\hline Parental concern & $-0.01 \quad(-0.02$ to 0.01$)$ & 0.3 \\
\hline Screen time & $0.09 \quad(-0.04$ to 0.21$)$ & 0.2 \\
\hline Supplements & $-0.01 \quad(-0.09$ to 0.07$)$ & 0.9 \\
\hline
\end{tabular}

Note: $\mathrm{BMI}=$ body mass index, $\mathrm{Cl}=$ confidence interval, $\mathrm{HDL}=$ high-density lipoprotein

*Adjusted for all other variables in the Table.

tChildren were assigned ethnicity based on the highest-risk ethnicity of their parents (see

Appendix 2, available at www.cmaj.ca/lookup/suppl/doi:10.1503/cmaj.121834/-/DC1). ated with serum non-HDL cholesterol levels (Table 4). However, the eating behaviours subscore was significantly associated with LDL cholesterol level and apolipoprotein B concentration (both of which are correlated with serum nonHDL cholesterol [correlation coefficients of 0.90 and 0.89 , respectively, $p<0.001]$ ). There was no association between the dietary intake subscale score and non-HDL cholesterol concentration.

\section{Interpretation}

Eating behaviours as reported by parents via the NutriSTEP questionnaire were positively associated with serum non-HDL cholesterol levels in children aged 3-5 years. The association between the eating behaviours subscore and serum non-HDL cholesterol persisted after controlling for age, sex, birth weight, zBMI, parental BMI, gestational diabetes and parental ethnicity. These results suggest that eating behaviours may be an important target for interventions to promote cardiovascular health in young children.

The importance of serum non-HDL cholesterol concentration in preschool-aged children has not been established, but several studies suggest that cholesterol concentrations can be used to predict later cardiovascular disease. ${ }^{9-12}$ We did not find an association between serum non-HDL cholesterol concentration and the dietary intake subscore of the NutriSTEP questionnaire, which is consistent with other studies involving young children that have shown an association between eating behaviours (e.g., bottle use) and iron deficiency outcomes that were independent of dietary intake (e.g., milk volume). ${ }^{21-23}$ These results raise the possibility that eating behaviours are more closely related to health outcomes than dietary intake. The relations between eating behaviours and LDL cholesterol and apolipopro-

Table 4: NutriSTEP subscores and beta estimates for laboratory indices from our regression models

\begin{tabular}{|c|c|c|c|c|c|}
\hline \multirow[b]{2}{*}{ NutriSTEP subscore } & \multicolumn{5}{|c|}{ Beta estimates $(95 \% \mathrm{Cl})$} \\
\hline & $\begin{array}{l}\text { Non-HDL } \\
\text { cholesterol }\end{array}$ & LDL cholesterol & Apolipoprotein B & HDL cholesterol & Apolipoprotein A1 \\
\hline Eating behaviours & $\begin{array}{c}0.02 \\
(0.002 \text { to } 0.05)\end{array}$ & $\begin{array}{c}0.02 \\
(0.002 \text { to } 0.05)\end{array}$ & $\begin{array}{c}0.01 \\
\text { (0.002 to } 0.01)\end{array}$ & $\begin{array}{c}-0.008 \\
(-0.02 \text { to } 0.001)\end{array}$ & $\begin{array}{c}-0.004 \\
(-0.01 \text { to } 0.003)\end{array}$ \\
\hline Dietary intake & $\begin{array}{c}-0.01 \\
(-0.02 \text { to } 0.01)\end{array}$ & $\begin{array}{c}-0.009 \\
(-0.02 \text { to } 0.004)\end{array}$ & $\begin{array}{c}-0.001 \\
(-0.004 \text { to } 0.002)\end{array}$ & $\begin{array}{c}0.002 \\
(0.004 \text { to } 0.008)\end{array}$ & $\begin{array}{c}0.003 \\
(-0.001 \text { to } 0.01)\end{array}$ \\
\hline Parental concern & $\begin{array}{c}-0.01 \\
(-0.02 \text { to } 0.01)\end{array}$ & $\begin{array}{c}-0.004 \\
(-0.02 \text { to } 0.01)\end{array}$ & $\begin{array}{c}-0.001 \\
(-0.01 \text { to } 0.004)\end{array}$ & $\begin{array}{c}0.004 \\
(-0.004 \text { to } 0.012)\end{array}$ & $\begin{array}{c}0.001 \\
(-0.01 \text { to } 0.01)\end{array}$ \\
\hline Screen time & $\begin{array}{c}0.09 \\
(-0.04 \text { to } 0.21)\end{array}$ & $\begin{array}{c}0.07 \\
(-0.05 \text { to } 0.19)\end{array}$ & $\begin{array}{c}0.002 \\
(-0.03 \text { to } 0.03)\end{array}$ & $\begin{array}{c}0.02 \\
(-0.04 \text { to } 0.07)\end{array}$ & $\begin{array}{c}0.01 \\
(-0.04 \text { to } 0.05)\end{array}$ \\
\hline Supplements & $\begin{array}{c}-0.01 \\
(-0.09 \text { to } 0.07)\end{array}$ & $\begin{array}{c}-0.01 \\
(-0.09 \text { to } 0.07)\end{array}$ & $\begin{array}{c}-0.01 \\
(-0.03 \text { to } 0.01)\end{array}$ & $\begin{array}{c}-0.01 \\
(-0.04 \text { to } 0.03)\end{array}$ & $\begin{array}{c}0.02 \\
(-0.02 \text { to } 0.05)\end{array}$ \\
\hline
\end{tabular}


tein $\mathrm{B}$ are not surprising given the correlation of these indices with serum non-HDL cholesterol concentration. ${ }^{12}$ In addition, apolipoprotein B is known to be correlated with cardiometabolic risk factors in adolescents. ${ }^{24}$

\section{Limitations}

Limitations of our cross-sectional study, which cannot show causality, include the recruitment of participants from primary care practices in Toronto who may not be representative of children in other settings.

In addition, a fraction of eligible children did not participate in the study because laboratory tests were declined by their parents (Figure 1). However, there were no significant differences between children for whom laboratory data were available and children for whom they were not. Furthermore, the participation rate for our study may reflect the realities of conducting research involving young children.

Furthermore, it is possible that our measure of dietary intake was too crude to detect associations or that parents have more difficulty with recall and reporting of dietary intake as compared with eating behaviours. Food records may be a better measurement tool for dietary intake, but they are more burdensome for parents.

The parents of the children involved in the study had a high mean level of education, which is not uncommon for women of childbearing age in Toronto. ${ }^{25}$

\section{Conclusion}

Our results support previous arguments for interventions aimed at improving the eating behaviours of preschool-aged children. To do so, evidence suggests promoting responsive feeding, where adults provide appropriate access to healthy foods and children use internal cues (not parentdirected cues or cues from the television) to determine the timing, pace and amount they consume. ${ }^{8}$

Our results also suggest that interventions that target preschool-aged children may be important in addition to the numerous schoolbased interventions aimed at older children and adolescents. ${ }^{26,27}$ Our results show that associations between eating behaviours and cardiovascular risk appear early in life and may be a potential target for early intervention. Future work may include determining how the association between eating behaviours and serum nonHDL cholesterol concentration changes over time, and ultimately whether eating behaviours during early childhood are associated with later cardiometabolic outcomes. This future work could facilitate the development of effective screening tools and interventions for early child- hood, long before the consequences of cardiometabolic disease manifest.

\section{References}

1. Gibson EL, Kreichauf S, Wildgruber A, et al. A narrative review of psychological and educational strategies applied to young children's eating behaviours aimed at reducing obesity risk. Obes Rev 2012;13(Suppl 1):85-95.

2. Wardle J, Cooke LJ, Gibson EL, et al. Increasing children's acceptance of vegetables: a randomized trial of parent-led exposure. Appetite 2003;40:155-62.

3. Jansen E, Mulkens S, Jansen A. How to promote fruit consumption in children. Visual appeal versus restriction. Appetite 2010; 54:599-602

4. Birch LL, Mcphee L, Shoba BC, et al. Clean up your plate effects of child feeding practices on the conditioning of meal size. Learn Motiv 1987;18:301-17.

5. Kral TV, Kabay AC, Roe LS, et al. Effects of doubling the portion size of fruit and vegetable side dishes on children's intake at a meal. Obesity (Silver Spring) 2010;18:521-7.

6. Greenhalgh J, Dowey AJ, Horne PJ, et al. Positive and negative peer modelling effects on young children's consumption of novel blue foods. Appetite 2009;52:646-53.

7. Hendy HM, Raudenbush B. Effectiveness of teacher modeling to encourage food acceptance in preschool children. Appetite 2000;34:61-76

8. McGuire S. Institute of Medicine (IOM) Early Childhood Obesity Prevention Policies. Washington, DC: The National Academies Press; 2011. Adv Nutr. 2012;3:56-57.

9. Integrated guidelines for cardiovascular health and risk reduction in children and adolescents. Bethesda (MD): National Heart Lung and Blood Institute; 2012. Available: www.nhlbi.nih.gov /guidelines/cvd_ped (accessed 2013 Apr. 16).

10. Raitakari OT, Juonala M, Kahonen M, et al. Cardiovascular risk factors in childhood and carotid artery intima-media thickness in adulthood: the Cardiovascular Risk in Young Finns Study. JAMA 2003;290:2277-83.

11. Juonala M, Viikari JS, Kahonen M, et al. Childhood levels of serum apolipoproteins B and A-I predict carotid intima-media thickness and brachial endothelial function in adulthood: the Cardiovascular Risk in Young Finns Study. J Am Coll Cardiol 2008;52:293-9.

12. Berenson GS, Srinivasan SR, Bao W, et al. Association between multiple cardiovascular risk factors and atherosclerosis in children and young adults. The Bogalusa Heart Study. N Engl J Med 1998;338:1650-6.

13. Randall Simpson JA, Keller HH, Rysdale LA, et al. Nutrition Screening Tool for Every Preschooler (NutriSTEP): validation and test-retest reliability of a parent-administered questionnaire assessing nutrition risk of preschoolers. Eur J Clin Nutr 2008;62:770-80.

14. Watson-Jarvis K, McNeil D, Fenton TR, et al. Implementing the Nutrition Screening Tool for Every Preschooler (NutriSTEP) in community health centres. Can J Diet Pract Res 2011;72:96-8.

15. Training course on child growth assessment. Geneva (Switzerland): World Health Organization; 2008. Available: www.who .int/childgrowth/training/module_c_interpreting_indicators.pdf (accessed 2013 Apr. 24)

16. de Onis M, Onyango A, Borghi E, et al. Worldwide implementation of the WHO Child Growth Standards. Public Health Nutr 2012;15:1603-10.

17. Anand SS, Yusuf S, Vuksan V, et al. Differences in risk factors, atherosclerosis, and cardiovascular disease between ethnic groups in Canada: the Study of Health Assessment and Risk in Ethnic groups (SHARE). Lancet 2000;356:279-84.

18. Balarajan R. Ethnic differences in mortality from ischaemic heart disease and cerebrovascular disease in England and Wales. BMJ 1991;302:560-4.

19. Little RJA, Rubin DB. Statistical analysis with missing data. 2nd ed. Hoboken (NJ): Wiley; 2002;41-53; 66-70; 85-9.

20. Harrell FE. Regression modeling strategies. New York (NY): Springer Science; 2001;48-9; 56-60.

21. Bonuck KA, Kahn R. Prolonged bottle use and its association with iron deficiency anemia and overweight: a preliminary study. Clin Pediatr (Phila) 2002;41:603-7.

22. Sutcliffe TL, Khambalia A, Westergard S, et al. Iron depletion is associated with daytime bottle-feeding in the second and third years of life. Arch Pediatr Adolesc Med 2006;160:1114-20.

23. Brotanek JM, Halterman JS, Auinger P, et al. Iron deficiency, prolonged bottle-feeding, and racial/ethnic disparities in young children. Arch Pediatr Adolesc Med 2005;159:1038-42.

24. Morrison JA, Glueck CJ, Daniels SR, et al. Determinants of ApoB, ApoA1, and the ApoB/ApoA1 ratio in healthy schoolgirls, prospectively studied from mean ages 10 to 19 years: the 
Cincinnati National Growth and Health Study. Metabolism 2012;61:1377-87.

25. Median total income, by family type, by census metropolitan area. Ottawa (ON): Statistics Canada; 2012. Available: www .statcan.gc.ca/tables-tableaux/sum-som/101/cst01/famil107a-eng .htm (accessed 2013 Apr. 14)

26. Birch LL, Ventura AK. Preventing childhood obesity: What works? Int J Obes (Lond) 2009;33(Suppl 1):S74-81.

27. Brown T, Summerbell C. Systematic review of school-based interventions that focus on changing dietary intake and physical activity levels to prevent childhood obesity: an update to the obesity guidance produced by the National Institute for Health and Clinical Excellence. Obes Rev 2009;10:110-41.

Affiliations: Keenan Research Centre (Persaud, Lebovic, Maguire), Li Ka Shing Knowledge Institute; the Department of Family and Community Medicine (Persaud), St. Michael's Hospital and the University of Toronto; the Division of Pediatric Medicine and the Pediatric Outcomes Research Team (PORT) (Maguire, Parkin, Birken), The Hospital for Sick Children; the Department of Pediatrics (Maguire, McCrindle, Parkin, Birken), the University of Toronto, Toronto, Ont.; Family Relations and Applied Nutrition (Randall Simpson), University of Guelph, Guelph, Ont.; and the Division of Cardiology (McCrindle), The Hospital for Sick Children, Toronto, Ont.

Contributors: All of the authors made substantial contributions to the conception and design of the study; the acquisition, analysis and interpretation of the data; and the drafting of the manuscript or its critical revision for important intel- lectual content. All of the authors approved the final version submitted for publication.

Funding: Overall support for the TARGet Kids! program was provided by the Canadian Institutes of Health Research (CIHR) Institute of Human Development, Child and Youth Health and the Institute of Nutrition Metabolism and Diabetes, as well as the St. Michael's Hospital Foundation. The Paediatric Outcomes Research Team is supported by a grant from The Hospital for Sick Children Foundation. Navindra Persaud was supported by a Banting Postdoctoral Fellowship from CIHR. The funding agencies had no role in the design, collection, analyses or interpretation of results of this study.

Acknowledgements: The authors thank the TARGet Kids! Collaboration Clinical Site Investigators and Steering Committee Members (Dr. Tony Barozzino, Dr. Anna Banerji, Dr. Gary Bloch, Dr. Douglas Campbell, Dr. Christopher Cavacuiti, Dr. Sohail Cheema, Dr. Brian Chisamore, Dr. Karoon Danayan, Dr. Anh Do, Dr. Mark Feldman, Dr. Sloane Freeman, Dr. Moshe Ipp, Dr. Sheila Jacobson, Dr. Margarita Lam Antoniades, Dr. Eddy Lau, Dr. Julia Orkin, Dr. Sharon Naymark, Dr. Patricia Neelands, Dr. Michael Peer, Dr. Marty Perlmutar, Dr. Michelle Porepa, Dr. Alana Rosenthal, Dr. Janet Saunderson, Dr. Michael Sgro, Dr. Susan Shepherd, Dr. Carolyn Taylor, Dr. Joanne Vaughan and Dr. Ethel Ying). Additional contributions were made by Azar Azad, Khosrow Adeli, Charmaine Camacho, Nadia Kabir, Kanthi Kavikondala, Tarandeep Malhi, Magda Melo, Subitha Rajakumaran, Juela Sejdo and Laurie Thompson. 